\title{
Coupling the high-complexity land surface model ACASA to the mesoscale model WRF
}

\author{
L. Xu ${ }^{1}$, R. D. Pyles ${ }^{2}$, K. T. Paw $\mathbf{U}^{2}$, S. H. Chen $^{2}$, and E. Monier ${ }^{1}$ \\ ${ }^{1}$ Joint Program on the Science and Policy of Global Change, Massachusetts Institute of Technology, Cambridge, \\ Massachusetts, USA \\ ${ }^{2}$ Department of Land, Air, and Water Resources, University of California Davis, Davis, California, USA \\ Correspondence to: L. Xu (liyixm@mit.edu)
}

Received: 7 February 2014 - Published in Geosci. Model Dev. Discuss.: 5 May 2014

Revised: 21 October 2014 - Accepted: 8 November 2014 - Published: 10 December 2014

\begin{abstract}
In this study, the Weather Research and Forecasting (WRF) model is coupled with the Advanced CanopyAtmosphere-Soil Algorithm (ACASA), a high-complexity land surface model. Although WRF is a state-of-the-art regional atmospheric model with high spatial and temporal resolutions, the land surface schemes available in WRF, such as the popular NOAH model, are simple and lack the capability of representing the canopy structure. In contrast, ACASA is a complex multilayer land surface model with interactive canopy physiology and high-order turbulence closure that allows for an accurate representation of heat, momentum, water, and carbon dioxide fluxes between the land surface and the atmosphere. It allows for microenvironmental variables such as surface air temperature, wind speed, humidity, and carbon dioxide concentration to vary vertically within and above the canopy.

Surface meteorological conditions, including air temperature, dew point temperature, and relative humidity, simulated by WRF-ACASA and WRF-NOAH are compared and evaluated with observations from over 700 meteorological stations in California. Results show that the increase in complexity in the WRF-ACASA model not only maintains model accuracy but also properly accounts for the dominant biological and physical processes describing ecosystem-atmosphere interactions that are scientifically valuable. The different complexities of physical and physiological processes in the WRF-ACASA and WRF-NOAH models also highlight the impact of different land surface models on atmospheric and surface conditions.
\end{abstract}

\section{Introduction}

Though the surface layer represents a very small fraction of the planet - only the lowest $10 \%$ of the planetary boundary layer - it has been widely regarded as a crucial component of the climate system (Stull, 1988; Mintz, 1981; Rowntree, 1991; de Noblet-Ducoudré et al., 2012). The interaction between the land surface (biosphere) and the atmosphere is therefore one of the most active and important aspects of the natural system. Vegetation at the land surface introduces complex structures, properties, and interactions to the surface layer. Vegetation heavily modifies surface exchanges of energy, gas, moisture, and momentum, developing the microenvironment in ways that distinguish vegetated surfaces from landscapes without vegetation. Such influences are known to occur on different spatial and temporal scales (Chen and Avissar, 1994; Pielke et al., 2002; Zhao et al., 2001; de Noblet-Ducoudré et al., 2012; Peel et al., 2010). In particular, often near-geostrophically balanced wind patterns are disrupted in the lower atmosphere when wind encounters vegetated surfaces, i.e., the winds slow down and change direction as a result of turbulent flows that develop within and near vegetated canopies (Wieringa, 1986; Pyles et al., 2004; Queck et al., 2012; Belcher et al., 2012).

Depending in part on the canopy height and structure, wind and turbulent flows also vary considerably across different ecosystems - even when each is presented with the same meteorological and astronomical conditions aloft. Gradients in heating, air pressure, and other forcings develop across heterogeneous landscapes, helping to sustain atmospheric motion. Since the surface layer is the only physical boundary in an atmospheric model, there is a general con- 
sensus that accurate simulations of atmospheric processes require detailed representations of the surface layer, and its terrestrial system. Models that account for the effects of the terrestrial system on climatic and atmospheric conditions are referred to as land surface models (LSMs).

Current land surface models, e.g., the widely used set of four schemes present in the Weather Research and Forecasting (WRF) model (five-layer thermal diffusion, Pleim-Xiu, Rapid Update Cycle, and the popular NOAH), often overly simplify the surface layer by using a single-layer "big-leaf" parameterization and other assumptions, usually based on some form of bulk Monin-Obukhov-type similarity theory (Chen and Dudhia, 2001a, b; Pleim and Xiu, 1995; Smirnova et al., 1997, 2000; Xiu and Pleim, 2001). None of the LSMs in WRF nor the LSMs in most regional climate models simulate carbon dioxide flux, even though it is largely recognized as a major contributor to the current climate change phenomenon and a controller of plant physiology. Plant transpiration in these models is often based on the Jarvis parameterization, in which the stomatal control of transpiration is a multiplicative function of meteorological variables such as temperature, humidity, and radiation (Jarvis, 1976). However, a large number of studies show that there is a strong linkage between the physiological process of photosynthetic uptake and the respiratory release of $\mathrm{CO}_{2}$ to plant transpiration through stomata (Zhan and Kustas, 2001; Houborg and Soegaard, 2004; Warren et al., 2011). As such, physiological processes related to $\mathrm{CO}_{2}$ exchange rates should be included in surface-layer representation of water and energy exchanges. While a majority of earth system models now use land surface models with interactive carbon cycles, the representation of the land surface is often simplified in these models (Anav et al., 2013). Oversimplification of surface processes and their impacts on the atmosphere in these land surface models will likely cause the models to misrepresent and poorly predict surface-atmosphere interactions. Furthermore, such models often require intense fine-tuning and optimization algorithms for their results to match observations (Duan et al., 1992).

Recent computer and model developments have greatly improved atmospheric modeling abilities, as progressively more complex planetary boundary layer and surface schemes with higher spatial and temporal resolutions are being implemented. However, the challenges involved in advancing the robustness of land surface models continue to limit the realistic simulation of planetary boundary layer forcings from vegetation, topography, and soil.

Some have argued that the increase in model complexity does not translate into higher accuracy due to the increase in uncertainty introduced by the large number of input parameters needed by the more process-based models (Raupach and Finnigan, 1988; Jetten et al., 1999; de Wit, 1999; Perrin et al., 2001). Even when model complexity does not yield increased accuracy of results, properly accounting for the dominant biological and physical processes describing ecosystem-atmosphere interactions still enhances the systematic understanding of land surface processes, especially if the model is to be used for simulating climate change. It is best to obtain results that are both accurate and defensible to the systemic understanding.

This study introduces the novel coupling of the mesoscale WRF model with the complex multilayer Advanced CanopyAtmosphere-Soil Algorithm (ACASA) model to improve the surface and atmospheric representation in a regional context. Beyond the complexity of the land surface scheme used, WRF-ACASA can simulate carbon dioxide fluxes and water fluxes using a high-complexity turbulence scheme. However, an evaluation of the fundamental representation of the surface meteorology in WRF-ACASA (such as temperature, dew point temperature, and relative humidity) is a necessary first step, and the evaluations of the water and carbon dioxide fluxes in WRF-ACASA will be presented in future work. For this reason, the objective of this study is to evaluate the newly coupled WRF-ACASA model's ability to simulate surface meteorology from the diurnal to seasonal cycle over a region with complex terrains and heterogeneous ecosystems, namely California.

\section{Models, methodology, and data}

\subsection{The Weather Research and Forecasting (WRF) model}

The mesoscale model used in this study is the Advanced Research WRF (ARW) model version 3.1. WRF is a state-ofthe-art, mesoscale numerical weather prediction and atmospheric research model developed via a collaborative effort of the National Center for Atmospheric Research (NCAR), the National Oceanic and Atmospheric Administration (NOAA), the Earth System Research Laboratory (ESRL), and other agencies. The WRF model contains a nearly complete set of compressible and non-hydrostatic equations for atmospheric physics (Chen and Dudhia, 2000) to simulate threedimensional atmospheric variables, and its vertical grid spacing varies in height with smaller spacing between the lower atmospheric layers than the upper atmospheric layers. It is commonly used to study air quality, precipitation, severe windstorm events, weather forecasts, and other atmospheric conditions (Borge et al., 2008; Thompson et al., 2004; Powers, 2007; Miglietta and Rotunno, 2005; Trenberth and Shea, 2006). The WRF model has flexible spatial and temporal resolutions as well as domain nesting, and is usually run at resolutions between 1 and $50 \mathrm{~km}$. Compared to the typical general circulation model (GCM) horizontal resolutions, between 1 and $5^{\circ}$ (equivalent to 100 and $500 \mathrm{~km}$ at the Equator), the WRF model is better suited for studying weather and climate at the regional scale.

Four different parameterizations of land surface processes are available in the WRF model. The more widely used and 
most sophisticated NOAH model employs simplistic physics compared to ACASA, being more akin to the set of ecophysiological schemes that include the Simple Biosphere model (SiB; Sellers et al., 1996) and the Biosphere-Atmosphere Transfer Scheme (BATS; Dickinson et al., 1993). There is only one vegetated surface layer in the NOAH scheme, along with four soil layers to calculate soil temperature and moisture. The big-leaf approach assumes the entire canopy has similar physical and physiological properties to a single big leaf; in addition, energy and mass transfers for the surface layer are calculated using simple surface physics (Noilhan and Planton, 1989; Holtslag and Ek, 1996; Chen and Dudhia, 2000). For example, the surface skin temperature is linearly extrapolated from a single surface energy balance equation, which represents the combined surface layer of ground and vegetation (Mahrt and Ek, 1984). Surface evaporation is computed using modified diurnally dependent PenmanMonteith equation from Mahrt and Ek (1984) and the Jarvis parameterization (Jarvis, 1976). In all single-layer models like NOAH, there is no interaction or mixing within the canopy regardless of the specified vegetation type. The current WRF LSMs are relatively simple, when compared to the higher-order closure model ACASA, and none of them calculate carbon flux. In contrast, the fully coupled WRF-ACASA model is capable of calculating carbon dioxide fluxes as well as the response of ecosystems to increases in carbon dioxide concentrations.

\subsection{The Advanced Canopy-Atmosphere-Soil Algorithm (ACASA)}

Compared to the simple NOAH, the ACASA model version 2.0 is a complex multilayer analytical land surface model, which simulates the microenvironmental profiles and turbulent exchange of energy, mass, $\mathrm{CO}_{2}$, and momentum within and above ecosystems. It represents the interaction between vegetation, soil, and the atmosphere based on physical and biological processes described from the scale of leaves (microscale), with final output applicable to horizontal scales on the order of 100 times the ecosystem vegetation height (i.e., hundreds of meters to around $1 \mathrm{~km}$ ). The surface layer is represented as a column model with multiple vertical layers extending to the lowest WRF sigma layer. The model has 10 vertical atmospheric layers above-canopy, 10 intra-canopy layers, and 4 soil layers. The complex, physically based model includes intricate surface processes such as canopy structure, turbulent transport, and mixing within and above the canopy and sublayers, as well as interactions between canopy elements and the atmosphere. Light and precipitation from the atmospheric layers above are intercepted, infiltrated, and reflected within the canopy layers. These along with other meteorological and environmental forcings are drivers of plant physiological responses. All model processes, including the ones described below, are linked nu- merically in a manner in which physics and physiology are dynamically coupled.

For each canopy layer, leaves are oriented in nine sunlit angle leaf classes (random spherical orientation) and one shaded leaf class in order to more accurately represent radiation transfer and leaf temperatures in a simulated variable array. This array aggregates the exchanges of sensible heat, water vapor, momentum, and carbon dioxide. The values of fluxes at each layer depend on those from all other layers, so the long-wave radiative and turbulence transfer equations are iterated until numerical equilibrium is reached. Shortwave radiation fluxes, along with associated arrays (probabilities of transmission, beam extinction coefficients, etc.) are not changed, while the sets of turbulence and physiological equations are iterated to numerical convergence.

Plant physiological processes, such as evapotranspiration, photosynthesis, and respiration, are calculated for each of the leaf classes and layers based on the simulated radiation field and the micrometeorological variables calculated in the previous iteration step. The default maximum rate of $\mathrm{RuBisCO}$ carboxylase activity, which controls plant physiological processes, is provided for each of the standardized vegetation types, although specific values of these parameters can be entered. Temperature, mean wind speed, carbon dioxide concentration, and specific humidity are calculated explicitly for each layer using the higher-order closure equations (Meyers and Paw U, 1986, 1987; Su et al., 1996).

In addition to accounting for the carbon dioxide flux, a key advanced component of the ACASA model is its higherorder turbulence closure scheme. The parameterizations of the fourth-order terms used to solve the prognostic thirdorder equations are described by assuming a quasi-Gaussian probability distribution as a function of second-moment terms (Meyers and Paw U, 1987). Included in the turbulence set is a representation of varying $\mathrm{CO}_{2}$ concentration with height as a part of the model's physiological responses. Compared to lower-order closure models, the higher-order closure scheme increases model accuracy by improving representations of the turbulent transport of energy, momentum, and water by both small and large eddies. In small-eddy theory or eddy viscosity, energy fluxes move down a local gradient; however, large eddies in the real atmosphere can transport flux against the local gradient.

Such counter-gradient flow is a physical property of large eddies associated with long-distance transport. For example, mid-afternoon intermittent ejection-sweep eddies cycling deep into a warm forest canopy with snow on the ground, from regions with air temperature values between that of the warm canopy and the cold snow surface, would result in overturning of eddies to transport relatively warm air from above and within the canopy to the snow surface below. The local gradient from the canopy to the above-canopy air would incorrectly indicate sensible heat going upwards instead of the actual heat flow down through the canopy due to the long turbulence scales of transport. These poten- 
tial counter-gradient transports are responsible for much of land surface evaporation, heat, carbon dioxide, and momentum fluxes (Denmead and Bradley, 1985; Gao et al., 1989). The ACASA model uses higher-order closure transport between multiple layers of the canopy to simulate non-local transport, allowing for the simulation of counter-gradient and down-gradient exchange. By comparison, the simple lowerorder turbulence closure model NOAH has only one surface layer. It is limited to only down-gradient transport and cannot mix within the canopy.

In the ACASA model, both rain and snow forms of precipitation are intercepted by the canopy elements in each layer. Some of the precipitation is retained on the leaf surfaces to modify the microenvironment of the layers for the next time step, depending on the precipitation amount, canopy storage capacity, and vaporization or sublimation rate. The remaining precipitation is distributed to the ground surface, influencing soil moisture and/or surface runoff as calculated by the layered soil model. The soil model physics in ACASA are very similar to the diffusion physics used in NOAH, but ACASA includes enhanced layering of the snowpack for more detailed thermal profiles throughout deep snow. This multilayer snow model allows for interactions between layers, and more effectively calculates energy distribution and snow hydrological processes (e.g., snow melt) when surface snow experiences higher or lower temperatures than the underlying snow layers. This is especially relevant over regions with high snow depth where snow is a significant source of water, such as the Sierra Nevada. The multilayer snow hydrology scheme has been well tested during the SNOWMIP project (Etchevers et al., 2004; Rutter et al., 2009), where ACASA performed at least as well as many snow models by accurately estimating the snow accumulation rate as well as the timing of snow melt in a wide range of biomes.

The stand-alone version of the ACASA model has been successfully applied to study sites across different countries, climate systems, and vegetation types. These include a 500year-old growth coniferous forest at the Wind River Canopy Crane Research Facility in Washington State (Pyles et al., 2000, 2004); a spruce forest in the Fichtel Mountains in Germany (Staudt et al., 2011), a maquis ecosystem in Sardinia near Alghero (Marras et al., 2008); and a grape vineyard in Tuscany near Montelcino, Italy (Marras et al., 2011).

\subsection{The WRF-ACASA coupling}

In an effort to improve the parameterization of land surface processes and their feedbacks with the atmosphere, ACASA is coupled to the mesoscale model WRF as a new land surface scheme. The schematic diagram of Fig. 1 represents the coupling between the two models. The WRF model provides meteorological variables as input forcing to the ACASA land surface model at the lowest WRF sigma layer. These variables include solar shortwave and terrestrial (atmospheric thermal long-wave) radiation, precipitation, humidity, wind

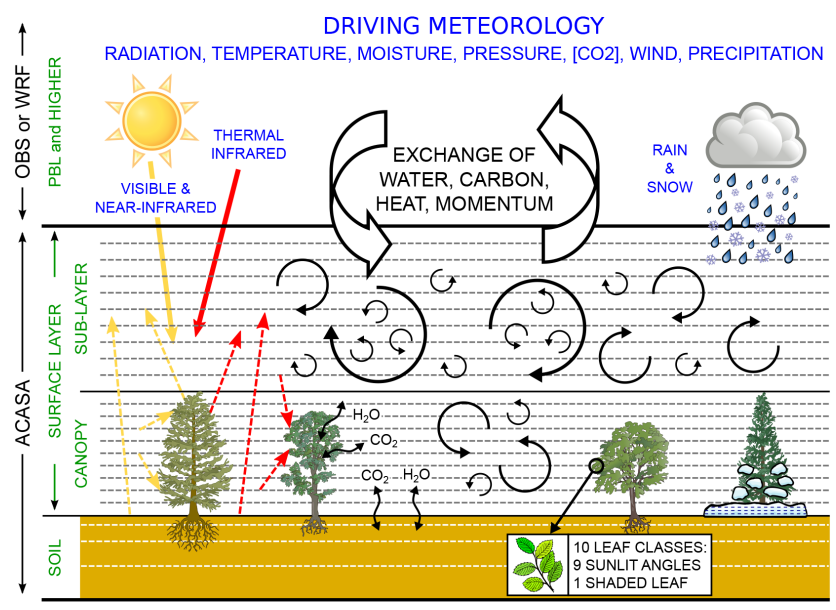

Figure 1. Schematic diagram of the WRF-ACASA coupling.

speed, carbon dioxide concentration, and barometric pressure. Radiation is partitioned into thermal IR, visible (PAR), and NIR by the ACASA model, which treats these radiation streams separately according to the preferential scattering of the different wavelengths as the radiation passes through the canopy. Part of the radiation is reflected back to the planetary boundary layer according to the layered canopy radiative transfer model, with the remaining radiation driving the canopy energy balance components and photosynthesis.

Both NOAH and ACASA use the same set of leaf area index (LAI) values from the WRF model. However, unlike the big-leaf model NOAH, ACASA creates a normalized vertical LAI or LAD (leaf area density for the multiple canopy layers according to vegetation type. Canopy height in ACASA is also prescribed based on vegetation type. This is crucial because the canopy height and distribution of LAD directly influence the interactions of wind, light, temperature, radiation, and carbon between the atmosphere and the surface layer.

\subsection{Model setup}

The WRF model requires input data for prognostic variables including wind, temperature, moisture, radiation, and soil temperature, both for an initialized field of variables through the domain, and at the boundaries of the domain. In this study, these input data are provided by the North America Regional Reanalysis (NARR) data set to drive both the WRF-NOAH and WRF-ACASA models. Unlike many other reanalysis data sets with coarse spatial resolution such as ERA-40 (European Centre for Medium-Range Weather Forecasts 40-year re-analysis) and GFS (Global Forecast System), NARR is a regional data set specifically developed for the North American region. The temporal and spatial resolutions of this data set are $3 \mathrm{~h}$ and $32 \mathrm{~km}$, respectively (Mesinger et al., 2006). 


\section{a) LEAF AREA INDEX}

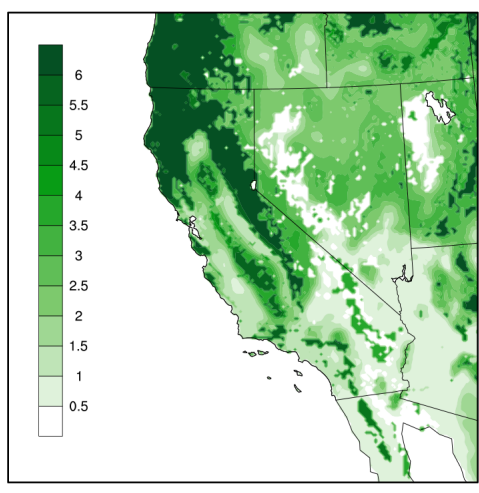

c) ARB OBSERVATIONAL STATIONS

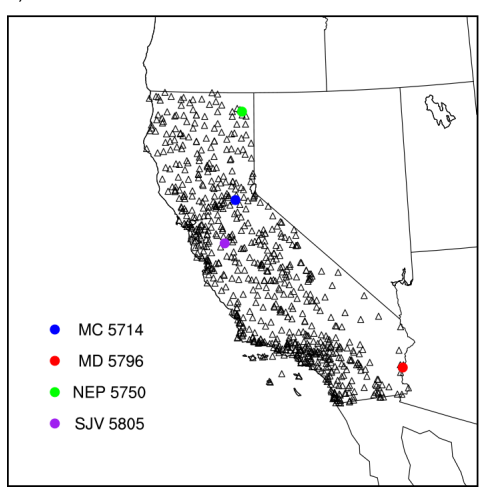

b) DOMINANT VEGETATION CATEGORY

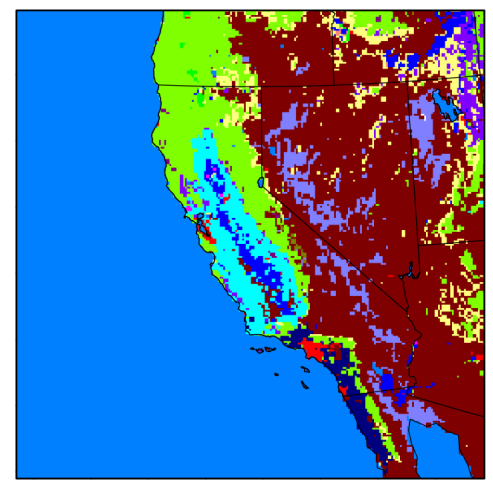

- URBAN AND BUILT-UP LAND $\square$ DRYLAND CROPLAND AND PASTURE - irigated chopland and pasture gomo pasture

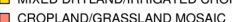
CROPLANDWOOSLLAND MOSAIC GRASSLAND GRASSLAND MIXED SHRUBLAND/GRASSLAND $\square$ SAVANNA

deciduous broadleaf Forest - DECIDUOUS NEEDLELEAF FOREST EVERGREEN BROADLEAF FOREST LVERGREEN NEEDLELEAF FORES MIXED FOREST HERBACEOUS WETLAND WOODED WETLAND BARREN OR SPARSELY VEGETATED - HERBACEOUS TUNDRA WOODED TUNDRA MIXED TUNDRA BARE GROUND TUNDRA SNOW OR ICE

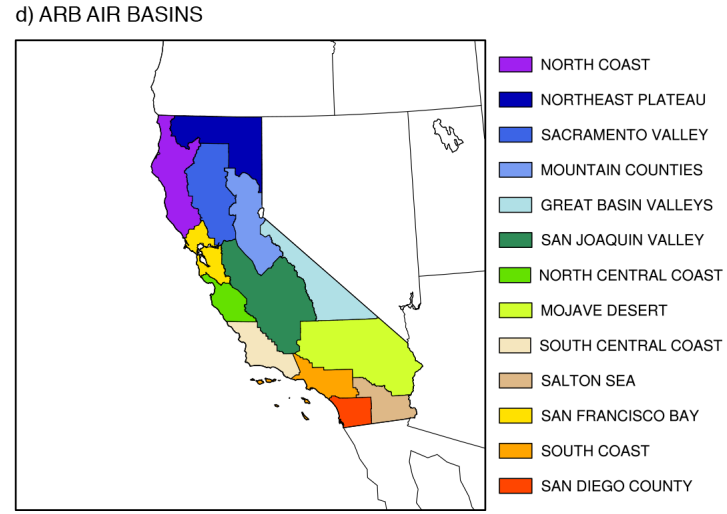

Figure 2. The complex topography and land cover of the study domain is represented here: (a) leaf area index (LAI) from USGS used by the WRF model, (b) dominant vegetation type, (c) ARB observational stations with the four selected stations shown (colored dots), and (d) map of the 13 ARB air basins.

Simulations with both the default WRF-NOAH and the WRF-ACASA models were performed for 2 years (2005 and 2006) with horizontal grid spacing of $8 \mathrm{~km} \times 8 \mathrm{~km}$. These 2 years were chosen because they provide the most extensive set of surface observation data. The model domain covers all of California with parts of neighboring states and the Pacific Ocean to the west, as shown in Fig. 2. The complex terrain and vast ecological and climatic systems in the region make this domain ideal for testing the performance of the WRFNOAH and WRF-ACASA models. The spatial resolution is chosen in order to resolve the major topographical and ecological features of the domain. The geological and ecological regions extend eastward from the coastal range shrublands to the Central Valley grasslands and croplands, then to the foothill woodlands before finishing at the coniferous forests along the Sierra Nevada range. Areas further inland to the east and south include the Great Basin and Mojave Desert, a semiarid and complex mosaic of forest and deserts shrublands tessellated amid the dunes and playas. The contrasting moist northern and semiarid southern Californian landscapes are also represented in tandem.

Aside from the differences in the land surface model, both WRF-NOAH and WRF-ACASA employ the same set of atmospheric physics schemes stemming from the WRF model.
These include the Purdue Lin et al. scheme for microphysics (Chen and Sun, 2002), the Rapid Radiative Transfer Model for long-wave radiation (Mlawer et al., 1997), the Dudhia scheme for shortwave radiation (Dudhia, 1989), the MoninObukhov similarity scheme for surface layer physics of nonvegetated surfaces and the ocean, and the MRF scheme for the planetary boundary layer (Hong and Pan, 1996). In this investigation, WRF was configured to run its atmospheric processes at a $60 \mathrm{~s}$ time step, while the radiation scheme and the land surface schemes are called every $30 \mathrm{~min}$. Because ACASA assumes quasi-steady-state turbulent processes, its physics are not considered advisable for shorter time intervals than $30 \mathrm{~min}$. Both NOAH and ACASA calculate surface processes and update the radiation balance, as well as heat flux, water vapor flux, carbon flux, surface temperature, snow water equivalent, and other surface variables in WRF. Analytical nudging of four-dimensional data assimilation (FDDA) is applied to the atmosphere above the planetary boundary layer for all model simulations in order to maintain the large-scale consistency and reduce drifting of model simulation from the driving field over time. Such nudging (FDDA) is commonly practiced in limited-area modeling, and current methods active in WRF are widely accepted due to rigorous testing (Stauffer and Seaman, 1990; Stauf- 
Table 1. Selected sites from the Air Resources Board meteorological stations network.

\begin{tabular}{lllll}
\hline Basin & Station ID & Latitude & Longitude & PFT \\
\hline MC & 5714 & 38.754 & -120.732 & Evergreen needleleaf forest \\
MD & 5796 & 33.532 & -114.634 & Shrubland \\
NEP & 5750 & 41.433 & -120.479 & Grassland \\
SJV & 5805 & 37.440 & -121.139 & Irrigated cropland and pasture \\
\hline
\end{tabular}

fer et al., 1991). In addition, WRF provides leaf area index (Fig. 2a) and land cover types (Fig. 2b) to both land surface models. Since NOAH is a single-layer model, canopy height is only used in ACASA and it is prescribed according to land cover type.

\subsection{Data}

The main independent observational data sets used to evaluate the model simulations were obtained from the Meteorological Section of the California Air Resources Board (ARB). The NARR data were not used for the evaluation as the data set was used for FDDA during both model simulations. The ARB meteorology data set is compiled from over 2000 surface observation stations in California from multiple agencies and programs: Remote Automated Weather Stations (RAWS) from the National Interagency Fire Center, the California Irrigation Management Information System (CIMIS), National Oceanic and Atmospheric Administration (NOAA), Aerometric Information Retrieval System (AIRS), and the Federal Aviation Administration. Potential measurement errors and uncertainties are expected in the ARB data because of the differences in station setups and measurement standards from the different agencies. For example, ambient surface air temperature is measured at various heights from 1 to $10 \mathrm{~m}$ above the ground, depending on the measuring agency. Some stations are located in urban environments, while the model simulations are structured to study natural vegetated environments. Therefore, some discrepancies between the observation and simulation are likely to occur in densely populated areas. However, with hourly data from over 2000 observation stations within the study domain, the ARB data set remains valuable. Out of the 2000 surface stations in the overall current ARB database, there were about 730 stations operational during the study period of 2005 and 2006 (Fig. 2c).

The meteorological and surface conditions from the WRFNOAH and WRF-ACASA model simulations are evaluated using the ARB data for the regional-scale level performance, and for specific basins and stations for more in-depth analysis. This represents the most rigorous test of ACASA to date, in terms of the sheer number of ACASA point simulations and the number of ACASA points linked in both space and time. This investigation therefore represents a significant elaboration upon earlier work (Pyles et al., 2003). Meteorological variables such as surface air temperature, dew point temperature, and relative humidity are evaluated against observational data for the two model simulations. At the time of the study, there are 13 air basins over California designated by the California Air Resources Board to represent regions of similar meteorological and geographical conditions. In this study, four basins are selected for more detailed analysis due to their distinct meteorological, geographic, and ecological attributes: the Northeast Plateau basin (NEP) is mostly grassland that covers $32 \%$ of the landscape; the Mojave Desert basin (MJ), located in southeastern California, is mostly shrubland with about $14 \%$ of vegetation cover; the San Joaquin Valley basin (SJV) is a major agricultural region, covered by irrigated cropland and pasture with about $23 \%$ of the land covered by vegetation; and the Sierra Nevada Mountains County basin (MC) with $60 \%$ of the land covered by high-altitude vegetation (mainly evergreen needleleaf forest). These four basins encompass a total of 240 stations. Measurements from these basins are compared to the WRF-NOAH and WRF-ACASA simulations output for the nearest grid points. From each basin, one station was identified for further detailed analysis (see Table 1 and Fig. 2c).

Observational data and model simulations output are available as hourly, and this study uses hourly, daily, and monthly analyses for model evaluation. Due to the nature of continuous instrument network operations, however, data gaps are inevitable in surface observations. To avoid missing data biases, only the days with complete $24 \mathrm{~h}$ data are used for statistical analyses. For example, a significant amount of missing data from daytime observation for the Mojave Desert station during June 2006 could skew the monthly mean temperature toward the cooler nighttime temperature if no data filter is applied and could result in a cold bias. By using only days with a complete $24 \mathrm{~h}$ of measurement for statistical analyses, the temperature bias toward any certain period of the day is avoided.

Some of the challenges in making a comparison between WRF-ACASA simulations and the observations are that (1) the observation heights were frequently different than the simulated grid point height, and (2) the station landscape type was often different than that of the simulation grid point. Some stations are within patches of specific landscape types that may differ significantly from the overall grid point landscape. Because the WRF-ACASA has multiple canopy layers, the $2 \mathrm{~m}$ height (surface) simulations may lie within the canopy or understory for taller plant ecosystems (such 


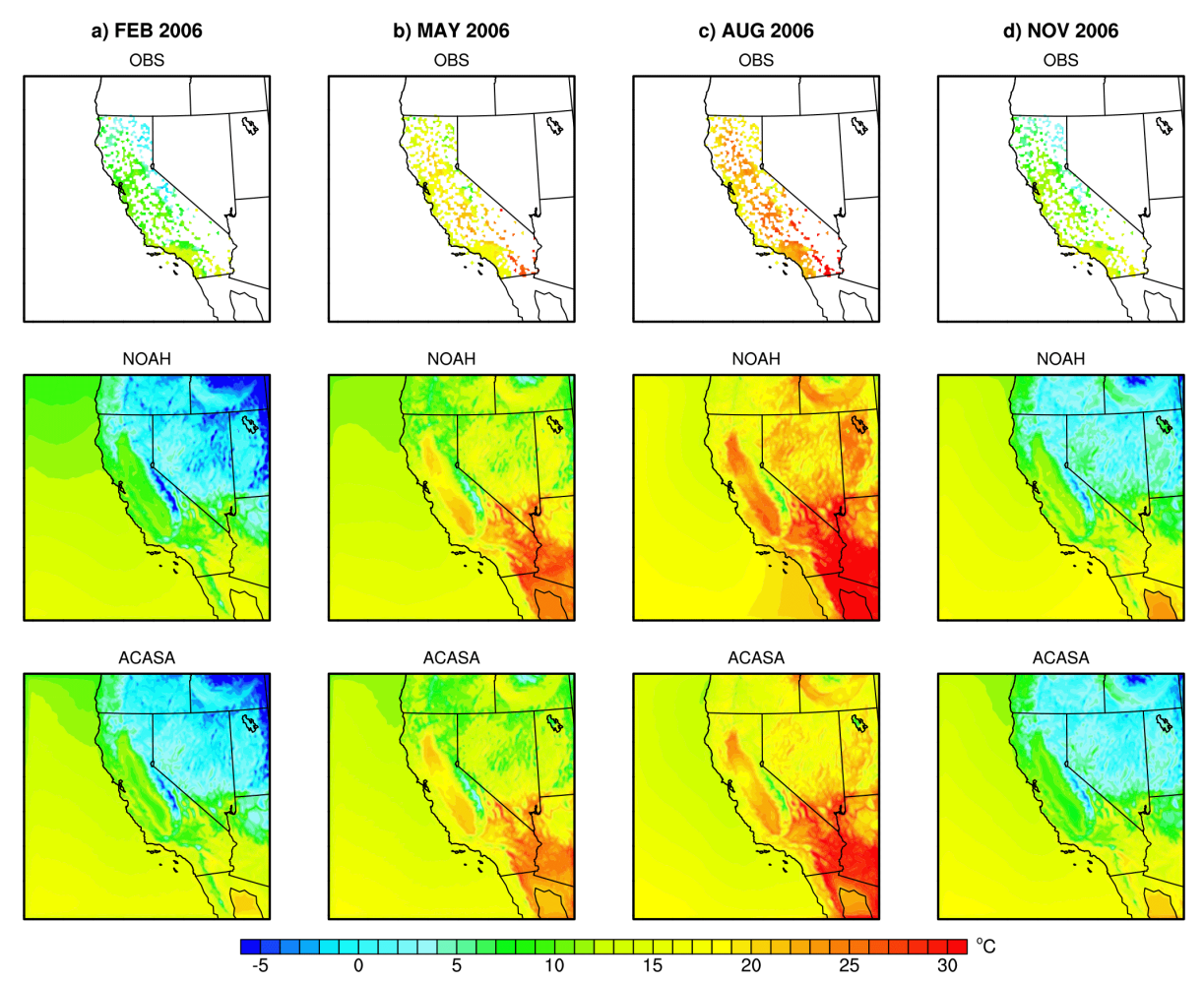

Figure 3. Monthly mean surface air temperature simulated by WRF-ACASA and WRF-NOAH and for the surface observations during the months of February, May, August, and November 2006.

as forests), although it never does for WRF-NOAH as the single-layer big-leaf model does not have understory; however, the measurements may be made at different heights and likely not within the canopy. It is, however, not feasible to use the WRF-ACASA simulated above-canopy temperature to emulate $2 \mathrm{~m}$ observed temperatures because the tall canopy turbulent transfer makes such physical analogies to shorter canopies inaccurate. Despite these shortcomings, the ARB data were chosen because of the large number of stations throughout the simulation domain. The results from year 2005 and year 2006 are similar, so only year 2006 is presented here.

\section{Results and discussion}

\subsection{Air temperature}

The spatial analyses of monthly mean surface temperature in California from both model simulations are compared against the surface observations in Fig. 3. The top panel shows the ARB data (measured at approximately 2 to $10 \mathrm{~m}$ above the ground); the white areas represent regions with missing observations. The WRF-NOAH and WRF-ACASA outputs are represented in the middle and lower rows, respectively. The aggregation of the high number of surface observations provides a regional-scale analysis of air temper- ature over California. The region's geographical complexity is highlighted by the spatial and temporal variations in the surface temperature. The warm summer and cool winter are typical of a Mediterranean-type climate. In addition to the seasonal variation, both WRF-ACASA and WRF-NOAH models are able to capture the distinct characteristics of the warm Central Valley (which includes the Sacramento Valley and San Joaquin Valley air basins from Fig. 2b) and semiarid region of southern California. The cold temperature over the mountain regions is also visible from the surface temperature field. The model simulations from WRF-ACASA and WRF-NOAH generally agree well with surface observations throughout the year. However, there are seasonal differences between the WRF-ACASA and the WRF-NOAH simulations.

During the month of February, the WRF-ACASA model simulates a slightly warmer region surrounding the Central Valley than the WRF-NOAH model. The temperature contrast of this region is mostly due to differences in land cover type, as well as LAI (Fig. 2). While both NOAH and ACASA use the same LAI and land cover data as WRF, ACASA distributes the LAI into multiple canopy layers of different vertical profiles according to canopy heights and vegetation types. These two variables highly influence plant physiological processes in the WRF-ACASA model such as photosynthesis, respiration, and evapotranspiration. Lower LAI in the area immediately surrounding the Central Valley has less leaf sur- 

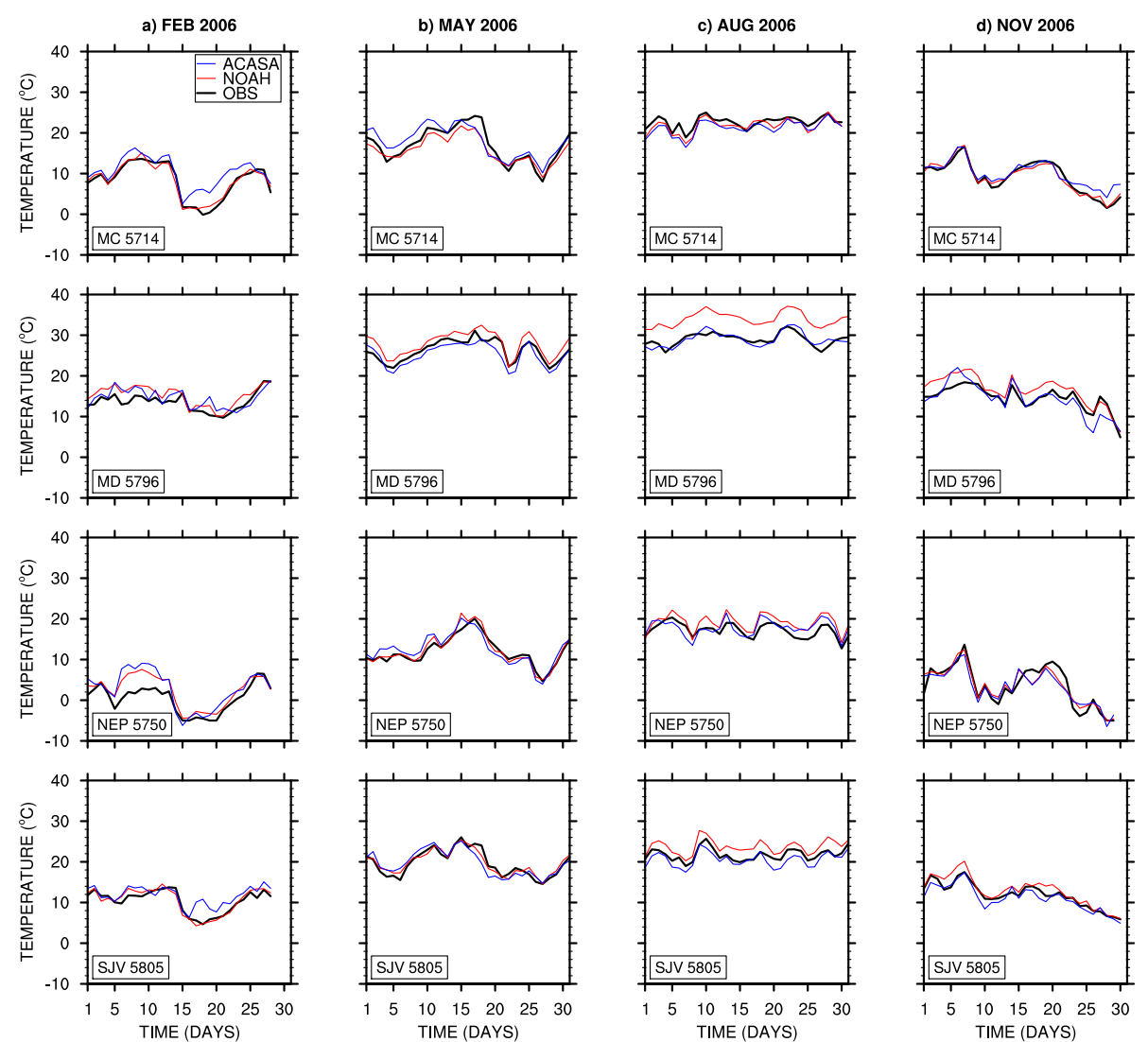

Figure 4. Time series of surface air temperature simulated by WRF-ACASA and WRF-NOAH and for the surface observations for four different stations and during the months of February, May, August, and November 2006. Observations are in black, the WRF-ACASA results are in blue and the WRF-NOAH results are in red. Rows from top to bottom: Mountain County station, Mojave Desert station, Northeast Plateau station, and San Joaquin Valley station.

face area for transpiration; therefore, it has higher partitioning of available energy to sensible heat.

On the other hand, the surface processes in WRF-NOAH rely heavily on the prescribed minimum canopy resistance for each vegetation type. As a result, the contrast in temperature between regions of different vegetation covers and LAI is more pronounced in the WRF-ACASA model than the WRF-NOAH model. Although WRF-ACASA is slightly cooler over the high-LAI region in the Central Valley during August, close examination in the Central Valley reveals that the prescribed LAI values in WRF are significantly higher than the remote sensing LAI values during the summer months. This discrepancy in LAI causes WRF-ACASA to overestimate evapotranspiration over the region and to create a cold bias. In contrast, the WRF-NOAH model is less sensitive to the LAI bias because of its simpler plant physiological processes. This highlights the conundrum of advancing model physics - more sophisticated models become more susceptible to errors in input data quality as they become more representative of variations in land cover type.

An in-depth analysis at basin and station levels is presented next for the two models. Figure 4 shows the compari- son between the two model simulations and observations for daily surface air temperature at four different stations (from the selected air basins from Table 1) during the months of February, May, August, and November 2006. Overall, both WRF-ACASA and WRF-NOAH perform well in simulating the day-to-day variations of temperature changes across the seasons and stations, with the exception of the Mojave Desert station. Even short-term weather events are clearly detectible in the simulated temperature changes. One such example is the Northeast Plateau station during the month of November, when it experiences a warming of $7-8^{\circ} \mathrm{C}$ in temperature followed by a $15^{\circ} \mathrm{C}$ plunge between day 5 and 10 . Both models are able to simulate this short-term weather event. However, the WRF-ACASA model is better in simulating air temperature over the Mojave Desert station during August, when WRF-NOAH overestimates the temperature by $5{ }^{\circ} \mathrm{C}$ for the entire month.

Figure 5 examines the differences in diurnal patterns from each station between the two land surface models over the four seasons. While the diurnal temperatures simulated by the two models fall mostly within the \pm 1 standard deviation range, the two models show small differences depend- 

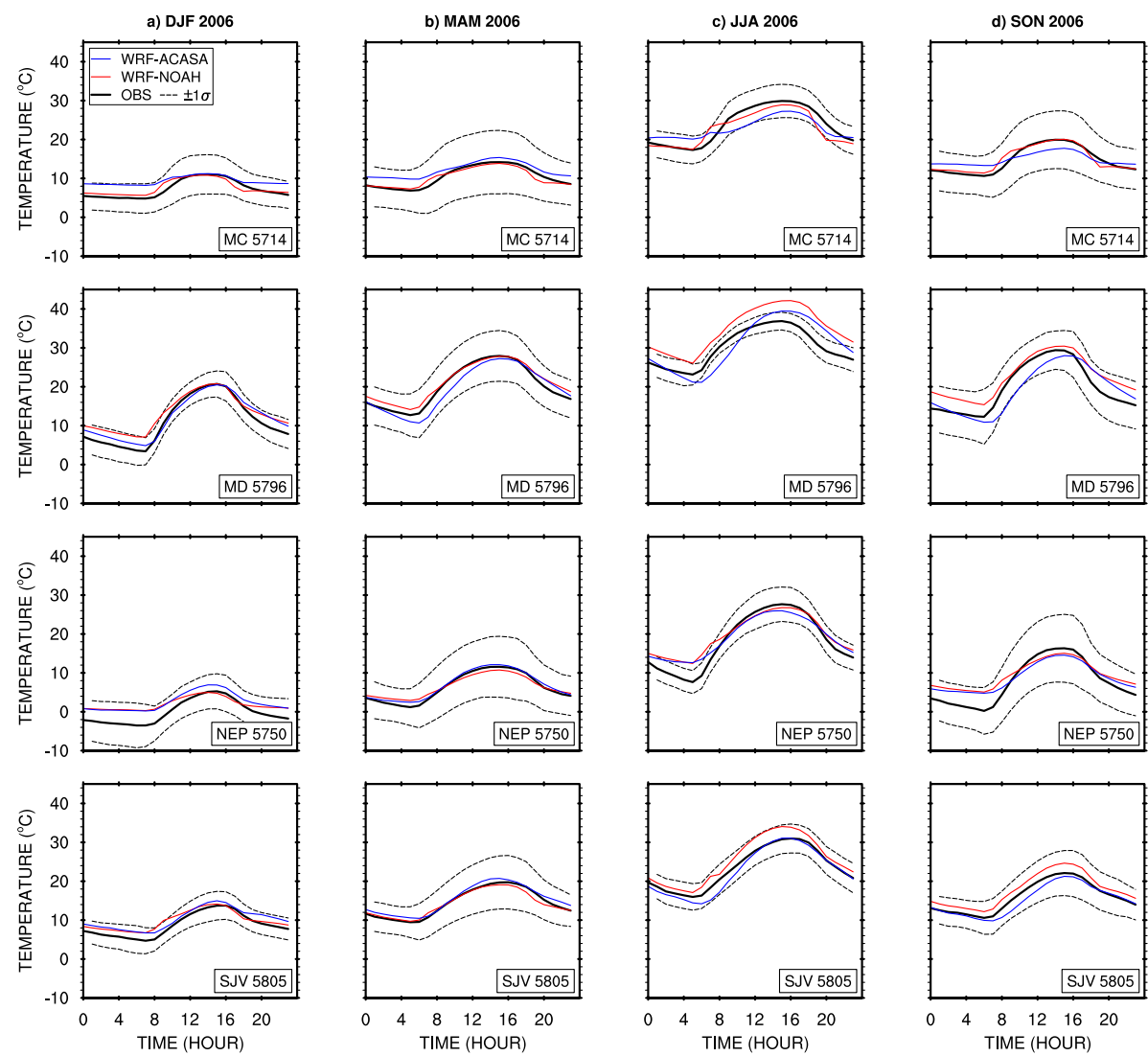

Figure 5. Diurnal cycle of surface air temperature for each season by station. The solid line and the two dashed black lines represent the surface observation and \pm 1 standard deviation from the mean, respectively. The WRF-ACASA results are in blue and the WRF-NOAH results are in red. Rows from top to bottom: Mountain County station, Mojave Desert station, Northeast Plateau station, and San Joaquin Valley station. Left to right: winter (DJF), spring (MAM), summer (JJA), and fall (SON).

ing on the season and location. The figure shows that during the summer, the WRF-ACASA model tends to underpredict temperature during the early morning in the Mojave Desert. On the other hand, the WRF-NOAH model systematically overpredicts temperature during most of the day, beyond 1 standard deviation, resulting in a significant warm bias. The differences between the two model simulations are likely the results from differences in the representation of land cover types, as well as canopy structure. While both WRF-ACASA and WRF-NOAH assign a shrubland plant functional type to the Mojave Desert site, the WRF-ACASA model also prescribes a $3 \mathrm{~m}$ canopy height to the shrubland vegetation type. Therefore, the surface of the Mojave Desert site takes longer to heat up in the morning in the WRF-ACASA model, because it is assumed to be within the canopy. This results in a lag of daytime temperature rise compared to the observed values. As the summer ends, the diurnal patterns of the WRFACASA model once again compare well with the observations, falling within the \pm 1 standard deviation. Because NOAH is a single-layer model, there is no canopy height or shading from canopy. As a result of its canopy structure, or rather lack of it, WRF-NOAH experiences rapid overheating at the Mojave Desert site during the summer.

Figure 6 shows scatterplots of monthly surface air temperature simulated by the WRF-ACASA and WRF-NOAH models versus observations, sorted by seasons, and for the same four basins defined previously (with a total of 240 stations). Each of the points represents a monthly average for one station in the specified basin, and the colors indicate seasons. Least-squares regression of the seasonal data shows that both model simulations approach a 1:1 line relationship with the observations. There are some small differences in performance between the two models depending on seasons and locations. This collective analysis of all stations from the four basins shows that, although there are some biases at station level, both models generally perform well across the entire basin. A more detailed analysis of air temperature for all 13 ARB air basins is given in the Supplement.

\subsection{Dew point temperature and relative humidity}

Similar to Fig. 4, Fig. 7 shows daily variations of surface dew point temperature over the same four stations (NEP, MD, 

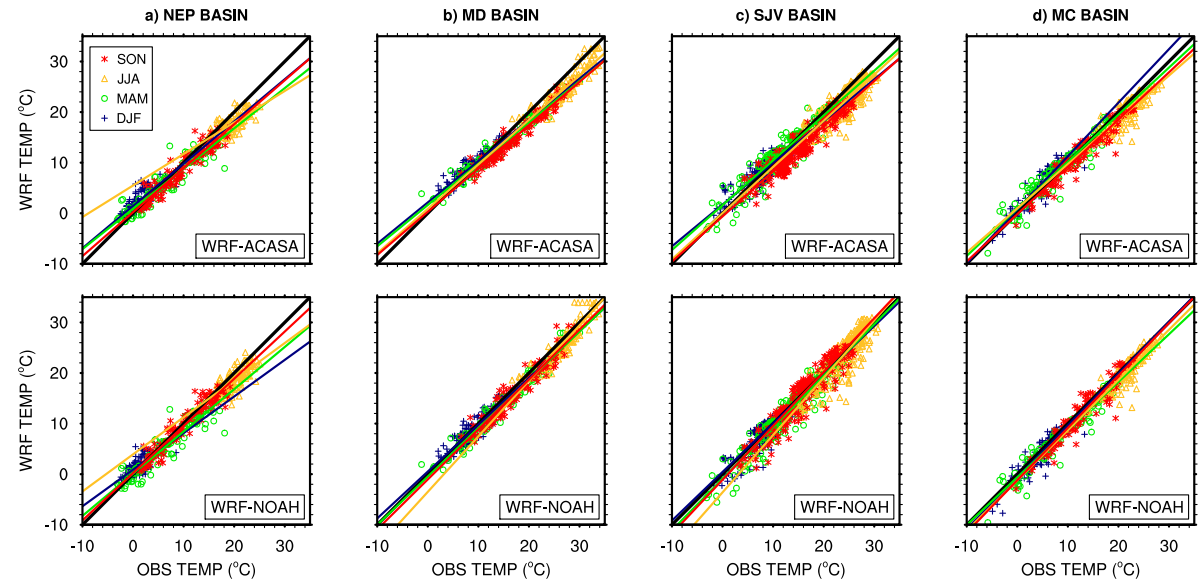

Figure 6. Scatterplots for monthly air temperature simulated by WRF-ACASA (top) and WRF-NOAH (bottom) for the all stations in the four basins: (left to right) Northeast Plateau station, Mojave Desert station, San Joaquin Valley station, and Mountain County station. Each colored shape represents a different season: blue cross - winter (DJF); green circle - spring (MAM); yellow triangle - summer (JJA); and red asterisk - fall (SON).
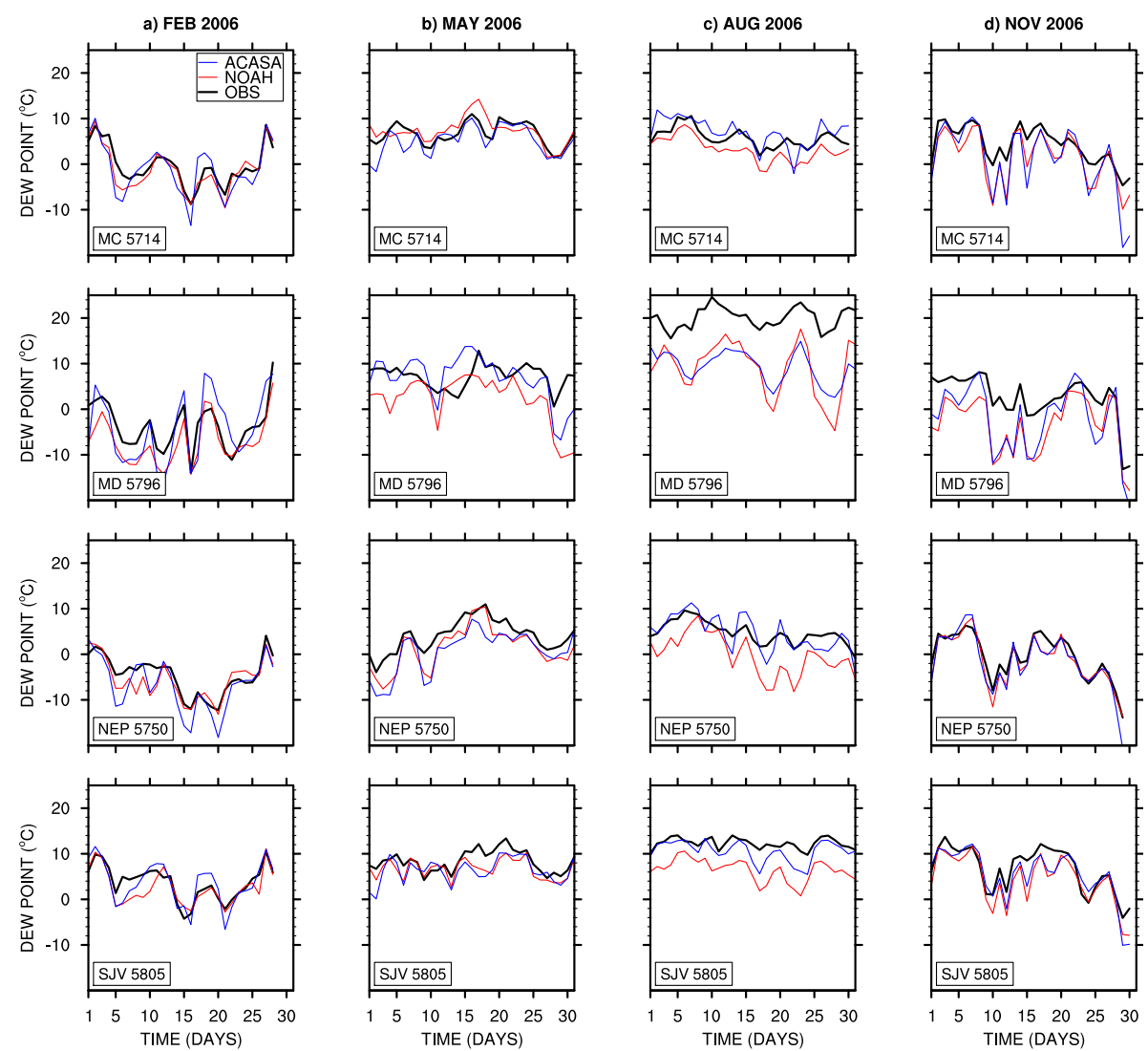

Figure 7. Time series of dew point temperature simulated by WRF-ACASA and WRF-NOAH and for the surface observations for four different stations and during the months of February, May, August, and November 2006. Observations are in black, the WRF-ACASA results are in blue and the WRF-NOAH results are in red. Rows from top to bottom: Mountain County station, Mojave Desert station, Northeast Plateau station, and San Joaquin Valley station. 

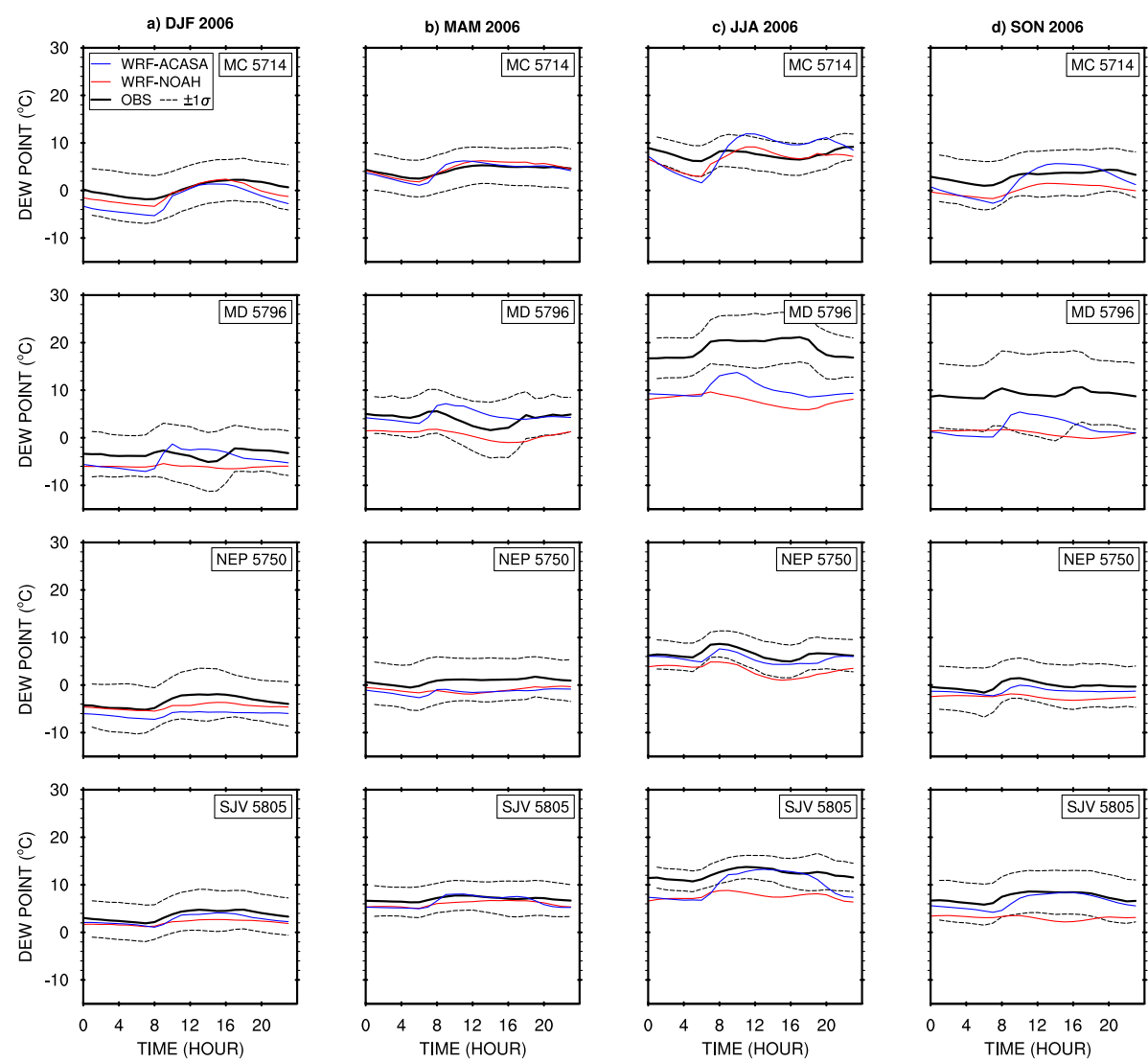

Figure 8. Diurnal cycle of dew point temperature for each season by station. The solid line and the two dashed black lines represent the surface observation and \pm 1 standard deviation from the mean, respectively. The WRF-ACASA results are in blue and the WRF-NOAH results are in red. Rows from top to bottom: Mountain County station, Mojave Desert station, Northeast Plateau station, San Joaquin Valley station. Left to right: winter (DJF), spring (MAM), summer (JJA), fall (SON).

SJV, MC) during the months of February, May, August, and November 2006. The dew point temperature influences land surface interaction with the atmosphere by indicating conditions for condensation. While both models perform well with the surface temperature simulation, the WRF-ACASA model outperforms the WRF-NOAH in simulating the dew point temperature, especially during the summer months for the MC, NEP, and SJV stations. A possible explanation is the complex physiological processes in the WRF-ACASA model that allow for a more accurate simulation of the humidity profile and physiological interactions. The multilayer canopy structure in the WRF-ACASA model is likely to retain moisture longer within the canopy. These details put the dew point temperature calculated by WRF-ACASA closer to observations than the WRF-NOAH model, which can only account for a single canopy layer. Both models have difficulty over the Mojave Desert station, where they underestimate the dew point temperature by as much as $15^{\circ} \mathrm{C}$ during August. Similar to the surface temperature analysis, both models perform well over the Northeast Plateau station with well-matched land cover types and simple canopy structure of short grass. In general, the dew point temperature simu- lated by the WRF-ACASA model displays better agreement with the observations than for the WRF-NOAH model.

Figure 8 presents diurnal patterns of surface dew point temperature for the four stations and four seasons. Unlike for the surface air temperature, there is relatively little diurnal variation in the surface dew point temperature throughout the seasons and locations. The dew point temperature simulated by the two models is a function of surface pressure and surface water vapor mixing ratio. Since the surface pressure does not change dramatically throughout the day, changes in dew point temperature are mainly due to fluctuations in water vapor mixing ratio. Once again, the dry arid and lowvegetated Mojave Desert site is problematic for both models during the summer. The disparities between the WRFACASA and WRF-NOAH models are more distinct in the diurnal dew point temperature than in the surface temperature: the dew point temperature simulated by WRF-ACASA is mostly within the \pm 1 standard deviation of observations, whereas WRF-NOAH tends to underestimate daytime dew point temperature.

Similar to Fig. 6, Fig. 9 shows scatterplots of monthly surface dew point temperature simulated by the WRF-ACASA 

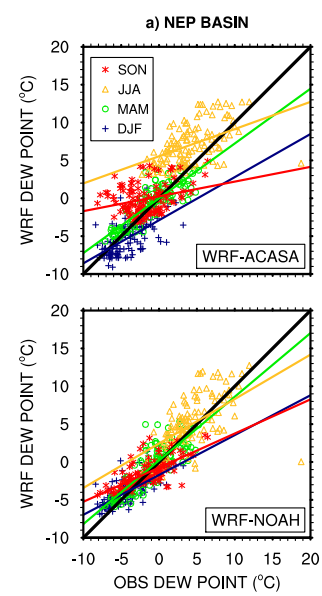

b) MD BASIN
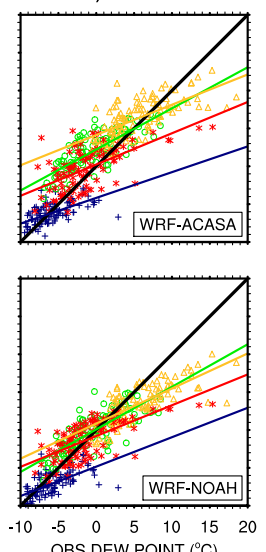

c) SJV BASIN
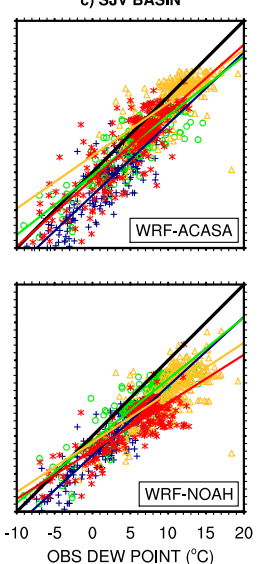

d) MC BASIN
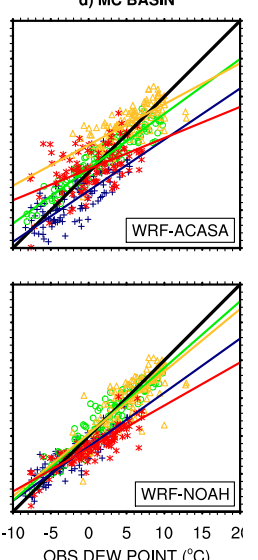

Figure 9. Scatterplots for monthly dew point temperature simulated by WRF-ACASA (top) and WRF-NOAH (bottom) for the all stations in the four basins: (left to right) Northeast Plateau station, Mojave Desert station, San Joaquin Valley station, and Mountain County station. Each colored shape represents a different season: blue cross - winter (DJF); green circle - spring (MAM); yellow triangle - summer (JJA); and red asterisk - fall (SON).

and WRF-NOAH versus observations, separated by seasons and basins. The dew point temperature simulated by the two models exhibit more scatter than the simulated surface air temperature. In addition, while the previous analyses of dew point temperature indicate that WRF-ACASA outperforms WRF-NOAH for specific stations (e.g., the MD and NEP stations), Fig. 9 shows that both models display similar performance at the basin scale. This suggests that the choice of land surface model has a substantial impact on individual stations, but not on the overall basin-wide biases. This decreased performance in the simulation of surface dew point temperature in both models could be the result of the assumption of horizontal homogeneity in each of the $8 \mathrm{~km} \times 8 \mathrm{~km}$ grid cells, which is used in both WRF-ACASA and WRF-NOAH. A single homogeneous grid cell could represent several observation stations with different microclimatic conditions. This is especially important when, for example, the shrublands in the Mojave Desert basin have different degrees of canopy openness.

Figure 10 compares the relative humidity simulated by WRF-ACASA and WRF-NOAH with surface observations at four different stations for the each season. Except for the Mojave Desert station during summer and fall, WRFACASA simulations generally fall within the \pm 1 standard deviation range of measured values for all stations and seasons. On the other hand, the WRF-NOAH model underestimates the relative humidity for both the Mojave Desert and San Joaquin Valley stations throughout the year. The higher relative humidity values in WRF-ACASA compared with WRF-NOAH during the warm season for these two stations reinforce the notion that the multilayer canopy structure and the higher-order turbulence closure scheme enable the simulation of the retention of more moisture within the canopy layers.
Figure 11 shows a Taylor diagram of monthly mean surface air temperature, dew point temperature, relative humidity, wind speed, and solar radiation simulated by WRFACASA and WRF-NOAH for all 730 stations in California. The Taylor diagram shows that simulations with both models agree well with surface measurements for every variable except wind speed. The surface air temperature, with high correlations, low RMSEs, and matching variability, is the most accurately simulated variable by both models. The WRFNOAH model shows slightly better performance for surface air temperature, while the WRF-ACASA model more accurately simulates dew point temperature and relative humidity. Both models simulate solar radiation with the same level of performance, mostly because the impact of the land surface model is limited on the atmospheric circulation and cloud cover. Finally, both models show low correlations and high root-mean-square errors for wind speed. These high rootmean-square errors and poor correlations could be attributed to the models' assumption of homogenous vegetation and the low resolution, which cannot capture local-scale turbulence at the station level.

\section{Conclusions}

In an effort to better represent land surface processes, the high-complexity land surface model ACASA is coupled with the state-of-art mesoscale model WRF. This study compares and evaluates the WRF model with two different land surface models, namely the high-complexity WRF-ACASA and the widely used, lower complexity WRF-NOAH. The evaluation focuses on the surface meteorological conditions over California from a regional to local scale. With vast differences in land cover, ecological, and climatological conditions, and with a complex terrain, California provides an ideal region 

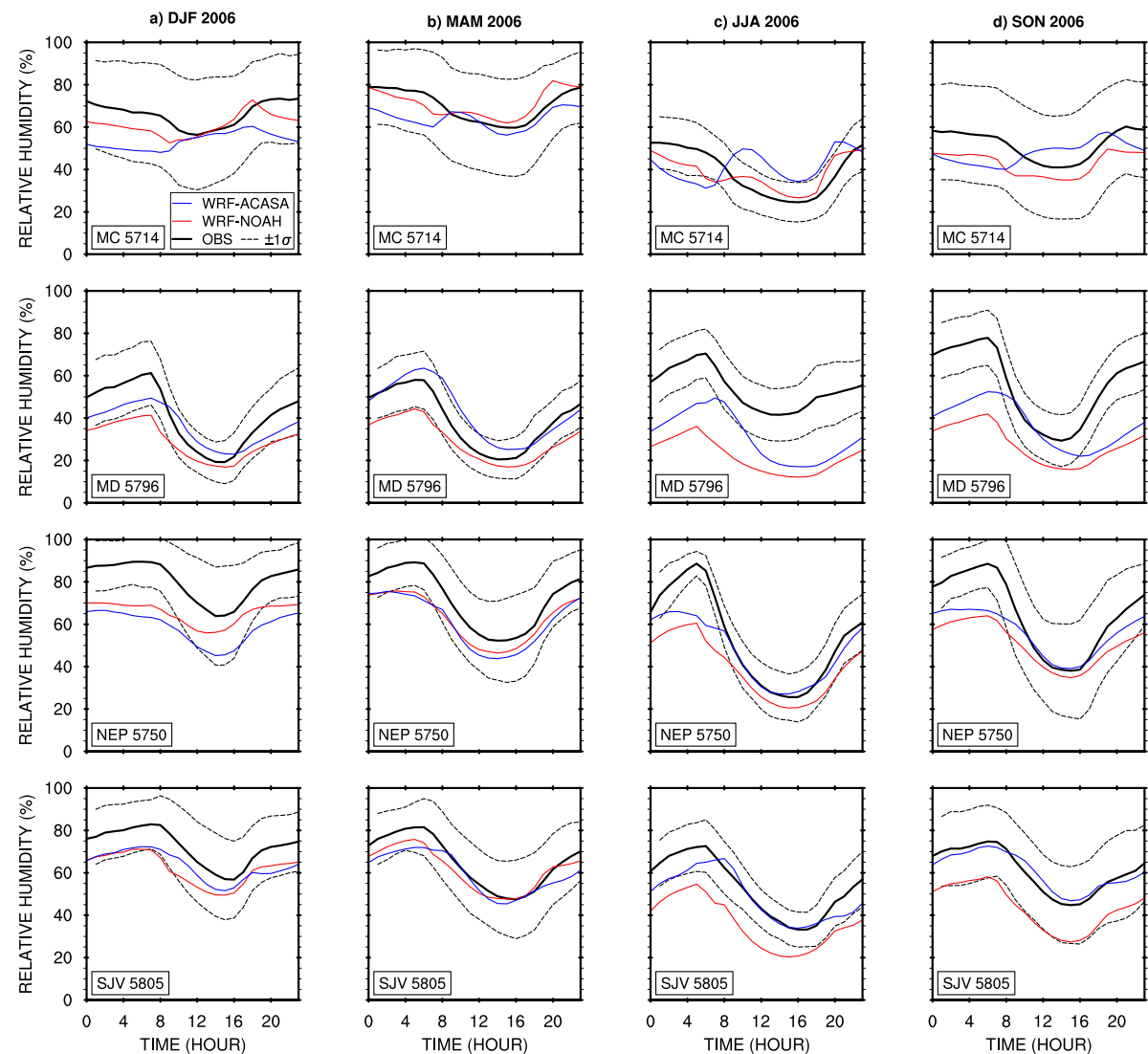

Figure 10. Diurnal cycle of relative humidity for each season by station. The solid line and the two dashed black lines represent the surface observation and \pm 1 standard deviation from the mean, respectively. The WRF-ACASA results are in blue and the WRF-NOAH results are in red. Rows from top to bottom: Mountain County station, Mojave Desert station, Northeast Plateau station, and San Joaquin Valley station. Left to right: winter (DJF), spring (MAM), summer (JJA), and fall (SON).

to test and evaluate both models. Simulations for both WRFACASA and WRF-NOAH at $8 \mathrm{~km} \times 8 \mathrm{~km}$ spatial resolution are compared with surface observations from over 700 stations of the ARB network for years 2005 and 2006.

Results show that the WRF-ACASA model is able to soundly simulate surface meteorological conditions. The simulation of temperature, dew point temperature, and relative humidity all agree well with the surface observations throughout various scales of analysis ranging from diurnal cycles, to day-to-day variability, to seasonal patterns.

Both model simulations agree well with the surface observations; however, there are small variations in model performance among land surface representations, depending on surface and atmospheric conditions. Overall, the WRFNOAH model displays a slightly better ability to simulate surface air temperature than WRF-ACASA; nonetheless, WRF-ACASA outperforms WRF-NOAH at the station level, such as over the Mojave Desert station during the summer season. At the same time, WRF-ACASA shows a more accurate simulation of dew point temperature and relative humidity compared to WRF-NOAH, especially during summer and fall seasons. The more complex and detailed canopy and plant physiological process parameterizations in ACASA appear to allow for the retention of more moisture within the canopy layers as well as the distribution of moisture within and above the canopy. As a result, WRF-ACASA may be better suited to simulate understory microclimate, as WRFNOAH's "big leaf" has no understory.

While the analysis presented in this study does not show any significant improvement in model performance from the simpler NOAH to the more complex ACASA model, this result echoes the results from the study of Jin et al. (2010), which compares the sensitivity of four different LSMs in WRF: the simple soil thermal diffusion (STD) scheme, the NOAH scheme, the Rapid Update Cycle (RUC) scheme, and the more sophisticated NCAR Community Land Model version 3 (CLM3). The study of Jin et al. (2010) shows that all four models perform similarly on snow water equivalent (SWE), temperature, and precipitation. In comparison, the high-complexity ACASA model presents a more detailed picture to properly account for the important biological and physical processes describing ecosystem-atmosphere interactions - including ecophysiological activities such as photosynthesis and respiration - without decreasing the quality 


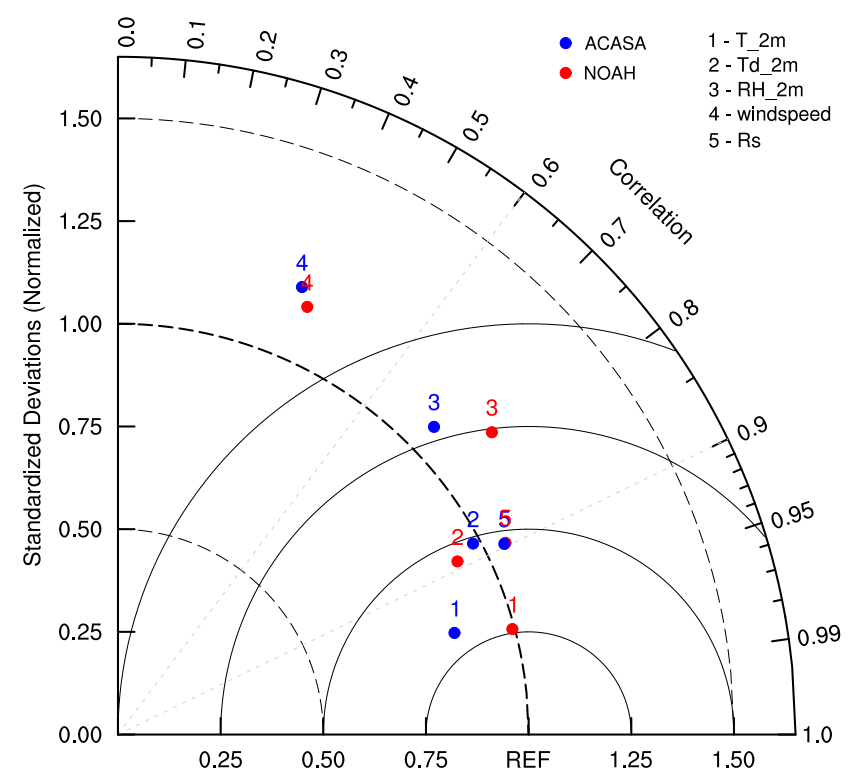

Figure 11. Taylor diagram of monthly mean surface air temperature, dew point temperature, relative humidity, wind speed, and solar radiation for both WRF-ACASA and WRF-NOAH for all ARB stations. WRF-ACASA is represented by blue dots and WRFNOAH by red dots.

of the output when compared to an extensive set of observations. Without tuning the ACASA model to any region, the model performs well and quantitatively similarly to the highly tuned and lower complexity NOAH model. The physical and physiological processes in WRF-ACASA also highlight the effect of different land surface components and their feedbacks to atmospheric processes. In particular, the highorder turbulence closure scheme in WRF-ACASA provides more detailed representation of eddy transport, and therefore it would better simulate exchanges of energy and fluxes between the atmosphere and the biosphere, as well as within the canopy layers. Beyond model complexity, the novel and exciting features of the WRF-ACASA model lie in its capability to simulate carbon dioxide and water fluxes at the regional scale. While this is not presented in this particular study, with focus on the more fundamental meteorological aspect of the land surface model, further evaluation of the carbon dioxide and water fluxes in WRF-ACASA is underway.

While this particular study focuses on California, the WRF-ACASA model can be used for any region of the world. As a result, the WRF-ACASA model provides opportunities for more studies on the topics of ecosystem response to human and natural disturbances, such as the contribution of irrigation to evapotranspiration and energy budget (see Falk et al., 2014), land use transformations, climate change, and other dynamic and biosphere-atmosphere interactions.

\section{Code availability}

The source code of the WRF-ACASA can be obtained upon request. The code can be compiled and run with platforms that support the WRF model. For code requests, please contact acasa-help@mit.edu.

\section{The Supplement related to this article is available online at doi:10.5194/gmd-7-2917-2014-supplement.}

Acknowledgements. This work is supported in part by the National Science Foundation under awards no. ATM-0619139 and EF1137306/MIT subaward 5710003122 to the University of California, Davis. The Joint Program on the Science and Policy of Global Change is funded by a number of federal agencies and a consortium of 40 industrial and foundation sponsors. (For the complete list see http://globalchange.mit.edu/sponsors/all).

We also thank Matthias Falk for his inputs on the WRF-ACASA work.

Edited by: M.-H. Lo

\section{References}

Anav, A., Friedlingstein, P., Kidston, M., Bopp, L., Ciais, P., Cox, P., Jones, C., Jung, M., Myneni, R., and Zhu, Z.: Evaluating the land and ocean components of the global carbon cycle in the CMIP5 Earth System Models, J. Climate, 26, 6801-6843, 2013.

Belcher, S. E., Harman, I. N., and Finnigan, J. J.: The wind in the willows: flows in forest canopies in complex terrain, Annu. Rev. Fluid Mech., 44, 479-504, 2012.

Borge, R., Alexandrov, V., José del Vas, J., Lumbreras, J., and Rodríguez, E.: A comprehensive sensitivity analysis of the WRF model for air quality applications over the Iberian Peninsula, Atmos. Environ., 42, 8560-8574, 2008.

Chen, F. and Avissar, R.: The impact of land-surface wetness heterogeneity on mesoscale heat fluxes, J. Appl. Meteorol., 33, 13231340, 1994.

Chen, F. and Dudhia, J.: Coupling an advanced land surfacehydrology model with the Penn State-NCAR MM5 modeling system. Part I: Model implementation and sensitivity, Mon. Weather Rev., 129, 569-585, 2001a.

Chen, F. and Dudhia, J.: Coupling an advanced land surfacehydrology model with the Penn State-NCAR MM5 modeling system. Part II: Preliminary model validation, Mon. Weather Rev., 129, 587-604, 2001b.

Chen, S. and Dudhia, J.: Annual report: WRF physics, Air Force Weather Agency, 2000.

Chen, S. and Sun, W.: A one-dimensional time dependent cloud model, J. Meteorol. Soc. Jpn., 80, 99-118, 2002.

Denmead, O. and Bradley, E.: Flux-gradient relationships in a forest canopy, in: The forest-atmosphere interaction: proceedings of the forest environmental measurements conference, edited by: Hutchison, B. and Hicks, B., 421-442, D. Reidel Publishing Company, Oak Ridge, TN, 1985. 
de Noblet-Ducoudré, N., Boisier, J.-P., Pitman, A., Bonan, G., Brovkin, V., Cruz, F., Delire, C., Gayler, V., van den Hurk, B., Lawrence, P., van der Molen, M., Müller, C., Reick, C., Strengers, B., and Voldoire, A.: Determining robust impacts of land-use-induced land cover changes on surface climate over North America and Eurasia: results from the first set of LUCID experiments, J. Climate, 25, 3261-3281, 2012.

de Wit, M.: Modelling nutrient fluxes from source to river load: a macroscopic analysis applied to the Rhine and Elbe basins, Hydrobiologia, 410, 123-130, 1999.

Dickinson, R., Henderson-Sellers, A., and Kennedy, P.: BiosphereAtmosphere Transfer Scheme (BATS) Version 1e as coupled to the NCAR community model, NCAR Tech. Note NCAR/TN387+ STR, 72, 1993.

Duan, Q., Sorooshian, S., and Gupta, V.: Effective and efficient global optimization for conceptual rainfall-runoff models, Water Resour. Res., 28, 1015-1031, 1992.

Dudhia, J.: Numerical study of convection observed during the winter monsoon experiment using a mesoscale two-dimensional model, J. Atmos. Sci., 46, 3077-3107, 1989.

Etchevers, P., Martin, E., Brown, R., Fierz, C., Lejeune, Y., Bazile, E., Boone, A., Dai, Y. J., Essery, R., Fernandez, A., Gusev, Y., Jordan, R., Koren, V., Kowalczyk, E., Nasonova, N. O., Pyles, R. D., Schlosser, A., Shmakin, A. B., Smirnova, T. G., Strasser, U., Verseghy, D., Yamazaki, T., and Yang, Z. L.: Validation of the energy budget of an alpine snowpack simulated by several snow models (SnowMIP project), Ann. Glaciol., 38, 150-158, 2004.

Falk, M., Pyles, R., Ustin, S., Paw U, K. T., Xu, L., Whiting, M., Sanden, B., and Brown, P.: Evaluated Crop Evapotranspiration over a Region of Irrigated Orchards with the Improved ACASAWRF Model, J. Hydrometeorol., 15, 744-758, 2014.

Gao, W., Shaw, R., and Paw U, K. T.: Observation of organized structure in turbulent flow within and above a forest canopy, Bound.-Lay. Meteorol., 47, 349-377, 1989.

Holtslag, A. and Ek, M.: Simulation of surface flux and boundary layer development over the pine forest in HAPEXMOBILHY, J. Appl. Meteorol., 35, 202-213, doi:10.1175/15200450(1996)035<0202:SOSFAB>2.0.CO;2, 1996.

Hong, S. and Pan, H.: Nonlocal boundary layer vertical diffusion in a medium-range forecast model, Mon. Weather Rev., 124, 2322 2339, 1996.

Houborg, R. and Soegaard, H.: Regional simulation of ecosystem $\mathrm{CO}_{2}$ and water vapor exchange for agricultural land using NOAA AVHRR and Terra MODIS satellite data. Application to Zealand, Denmark, Remote Sens. Environ., 93, 150-167, 2004.

Jarvis, P.: The interpretation of the variations in leaf water potential and stomatal conductance found in canopies in the field, Philos. T. Roy. Soc. London A, 273, 593-610, 1976.

Jetten, V., de Roo, A., and Favis-Mortlock, D.: Evaluation of fieldscale and catchment-scale soil erosion models, Catena, 37, 521$541,1999$.

Jin, J., Miller, N. L., and Schlegel, N.: Sensitivity study of four land surface schemes in the WRF model, Adv. Meteorol., 2010, 167436, doi:10.1155/2010/167436, 2010.

Mahrt, L. and Ek, M.: The influence of atmospheric stability on potential evaporation, Collections, 1984.

Marras, S., Spano, D., Sirca, C., Duce, P., Snyder, R., Pyles, R., and Paw U, K. T.: Advanced-Canopy-Atmosphere-Soil Algo- rithm (ACASA model) for estimating mass and energy fluxes, Ital. J. Agron., 3, 793-794, 2008.

Marras, S., Pyles, R., Sirca, C., Paw U, K. T., Snyder, R., Duce, P., and Spano, D.: Evaluation of the Advanced CanopyAtmosphere-Soil Algorithm (ACASA) model performance over Mediterranean maquis ecosystem, Agr. Forest Meteorol., 151, 730-745, 2011.

Mesinger, F., DiMego, G., Kalnay, E., Mitchell, K., Shafran, P. C., Ebisuzaki, W., Jovic, D., Woollen, J., Rogers, E., Berbery, E. H., Ek, M. B., Fan, Y., Grumbine, R., Higgins, W., Li, H., Lin, Y., Manikin, G., Parrish, D., and Shi, W.: North American regional reanalysis, B. Am. Meteorol. Soc., 87, 343-360, 2006.

Meyers, T. and Paw U, K. T.: Testing of a Higher-Order Closure Model for Modeling Airflow within and above Plant Canopies, Bound.-Lay. Meteorol., 37, 297-311, 1986.

Meyers, T. and Paw U, K. T.: Modelling the plant canopy micrometeorology with higher-order closure principles, Agr. Forest Meteorol., 41, 143-163, 1987.

Miglietta, M. and Rotunno, R.: Simulations of moist nearly neutral flow over a ridge, J. Atmos. Sci., 62, 1410-1427, 2005.

Mintz, Y.: A brief review of the present status of global precipitation estimates, in: Report of the Workshop on Precipitation Measurements from Space, edited by: Atlas, D. and Theile, O. W., T., NASA Goddard Space Flight Center, Greenbelt, MD, 1981.

Mlawer, E., Taubman, S., Brown, P., Iacono, M., and Clough, S. Radiative transfer for inhomogeneous atmospheres: RRTM, a validated correlated-k model for the longwave, J. Geophys. Res., 102, 16663-16682, doi:10.1029/97JD00237, 1997.

Noilhan, J. and Planton, S.: A simple parameterization of land surface processes for meteorological models, Mon. Weather Rev., 117, 536-549, 1989.

Peel, M. C., McMahon, T. A., and Finlayson, B. L.: Vegetation impact on mean annual evapotranspiration at a global catchment scale, Water Resour. Res., 46, W09508, doi:10.1029/2009WR008233, 2010.

Perrin, C., Michel, C., and Andréassian, V.: Does a large number of parameters enhance model performance? Comparative assessment of common catchment model structures on 429 catchments, J. Hydrol., 242, 275-301, 2001.

Pielke, R. A., Marland, G., Betts, R. A., Chase, T. N., Eastman, J. L., Niles, J. O., and Running, S. W.: The influence of landuse change and landscape dynamics on the climate system: relevance to climate-change policy beyond the radiative effect of greenhouse gases, Philos. T. Royal Soc. A, 360, 1705-1719, doi:10.1098/rsta.2002.1027, 2002.

Pleim, J. and Xiu, A.: Development and testing of a surface flux and planetary boundary layer model for application in mesoscale models, J. Appl. Meteorol., 34, 16-32, 1995.

Powers, J.: Numerical prediction of an Antarctic severe wind event with the Weather Research and Forecasting (WRF) model, Mon. Weather Rev., 135, 3134-3157, 2007.

Pyles, R., Weare, B., and Paw U, K. T.: The UCD Advanced Canopy-Atmosphere-Soil Algorithm: comparisons with observations from different climate and vegetation regimes, Q. J. Roy. Meteorol. Soc., 126, 2951-2980, 2000.

Pyles, R., Weare, B., Paw U, K. T., and Gustafson, W.: Coupling between the University of California, Davis, Advanced CanopyAtmosphere-Soil Algorithm (ACASA) and MM5: Preliminary 
results for July 1998 for western North America, J. Appl. Meteorol., 42, 557-569, 2003.

Pyles, R., Paw U, K. T., and Falk, M.: Directional wind shear within an old-growth temperate rainforest: observations and model results, Agr. Forest Meteorol., 125, 19-31, 2004.

Queck, R., Bienert, A., Maas, H.-G., Harmansa, S., Goldberg, $\mathrm{V}$., and Bernhofer, C.: Wind fields in heterogeneous conifer canopies: parameterisation of momentum absorption using highresolution 3D vegetation scans, European J. Forest Res., 131, 165-176, 2012.

Raupach, M. and Finnigan, J.: "Single-layer models of evaporation from plant canopies are incorrect but useful, whereas multilayer models are correct but useless": Discuss, Aust. J. Plant Physiol., 15, 705-716, 1988.

Rowntree, P.: Atmospheric parameterization schemes for evaporation over land: Basic concepts and climate modeling aspects, in: Land Surface Evaporation: Measurement and Parameterization, edited by: Schmugge, T. and André, J.-C., 5-29, Springer-Verlag, New York, 1991.

Rutter, N., Essery, R., Pomeroy, J., et al.: Evaluation of forest snow processes models (SnowMIP2), J. Geophys. Res., 114, D06111, doi:10.1029/2008JD011063, 2009.

Sellers, P., Tucker, C., Collatz, G., Los, S., Justice, C., Dazlich, D., and Randall, D.: A revised land surface parameterization (SiB2) for atmospheric GCMs. Part II: The generation of global fields of terrestrial biophysical parameters from satellite data, J. Climate, 9, 706-737, 1996.

Smirnova, T., Brown, J., and Benjamin, S.: Performance of different soil model configurations in simulating ground surface temperature and surface fluxes, Mon. Weather Rev., 125, 1870-1884, 1997.

Smirnova, T., Brown, J., Benjamin, S., and Kim, D.: Parameterization of cold-season processes in the MAPS, J. Geophys. Res., 105, 4077-4086, 2000.

Staudt, K., Serafimovich, A., Siebicke, L., Pyles, R., and Falge, E.: Vertical structure of evapotranspiration at a forest site (a case study), Agr. Forest Meteorol., 151, 709-729, 2011.
Stauffer, D. and Seaman, N.: Use of four-dimensional data assimilation in a limited-area mesoscale model. Part I: Experiments with synoptic-scale data, Mon. Weather Rev., 118, 1250-1277, 1990.

Stauffer, D., Seaman, N., and Binkowski, F.: Use of fourdimensional data assimilation in a limited-area mesoscale model. II - Effects of data assimilation within the planetary boundary layer, Mon. Weather Rev., 119, 734-754, 1991.

Stull, R. B.: An introduction to boundary layer meteorology, Kluwer Academic Publishers, 1988.

Su, H., Paw U, K. T., and Shaw, R.: Development of a coupled leaf and canopy model for the simulation of plant-atmosphere interactions, J. Appl. Meteorol., 35, 733-748, 1996.

Thompson, S., Govindasamy, B., Mirin, A., Caldeira, K., Delire, C., Milovich, J., Wickett, M., and Erickson, D.: Quantifying the effects of $\mathrm{CO}_{2}$-fertilized vegetation on future global climate and carbon dynamics, Geophys. Res. Lett., 31, L23211, doi:10.1029/2004GL021239, 2004.

Trenberth, K. and Shea, D.: Atlantic hurricanes and natural variability in 2005, Geophys. Res. Lett., 33, L12704, doi:10.1029/2006GL026894, 2006.

Warren, J. M., Pötzelsberger, E., Wullschleger, S. D., Thornton, P. E., Hasenauer, H., and Norby, R. J.: Ecohydrologic impact of reduced stomatal conductance in forests exposed to elevated $\mathrm{CO}_{2}$, Ecohydrology, 4, 196-210, 2011.

Wieringa, J.: Roughness-dependent geographical interpolation of surface wind speed averages, Q. J. Roy. Meteorol. Soc., 112, 867-889, 1986.

Xiu, A. and Pleim, J.: Development of a land surface model. Part I: Application in a mesoscale meteorological model, J. Appl. Meteorol., 40, 192-209, 2001.

Zhan, X. and Kustas, W.: A coupled model of land surface $\mathrm{CO}_{2}$ and energy fluxes using remote sensing data, Agr. Forest Meteorol., 107, 131-152, 2001.

Zhao, M., Pitman, A., and Chase, T.: The impact of land cover change on the atmospheric circulation, Clim. Dynam., 17, 467477, 2001. 